Chorea and hysteria are, however, the nervous disorders in which bromide of camphor has been most extensively used, and with the beet effects. Amongst the cases published on chorea are to be noted particularly those of Desnos, Gallard, des Brulais, and Petrovitz. In one case the patient, a child eleven years old, had been put with no result under the action of bark wine and of extract of belladonna (in doses of $\frac{1}{6} \mathrm{gr}$. to $1 \frac{1}{3} \mathrm{gr}$. a day. Bromide of camphor, in the form of Dr. Clin's dragées, was administered in increasing doses of from one to eight a day. At the end of a week the improvement was manifest, and after twelve days all the symptoms had disappeared.*

As regards the phenomena of hysteria, Riemer speaks of bromide of camphor with praise in reference to a case of hysterical excitement. Bourneville also mentions the successful use of the drug in cases of epileptic delirium in females to whom he administered the bromide in enemata containing from fifteen to sixty grains of the remedy, or in the shape of Clin's capsules of camphor. Tommasi has noted good effects in a case of hysteria with genital erethism, and Hammond in a case of chronic hysteria. Dr. Pathanlt has collected in his inaugural thesis, pnblished in Paris last year, a number of cases communicated by Professors Vulpian, Lorain, and Potain, and Dr. Mathieu, all of which show the benefit afforded in hysteria by the methodical nae of the drug. In a case recorded by Dr. Lepine, of Beaujon Hospital, a young hysterical girl, subject to fits of sometimes three hours' duration, and to whom a dose of more than onedrachm of bromide of potassium was given in the twenty-four hours with no effect, got better under the daily use of five of Dr. Clin's capsules (fitteen grains of the bromide). Certain forms of neuralgia, dyspncea of a nervous origin, and nervous palpitations, are said to have been also favourably affected by the use of the bromide.

Turning to anotber class of disease-namely, affections of the urino-genital organs-we find that in a case of vesical and anal tenesmus, dependent on peri-nterine phlegmon, Dr. Siredey, of Lariboisière Hospital, has recorded tine successful employment of the bromide. "In cystitis of the neck of the bladder," writes Dr. Lannelongue, "the action of bromide of camphor speedily shows itself-1. When cystitis is painful, and the pain is not dependent on any organic lesion (neuralgic cystitis). 2. In cystitis of the neck, having a congestive cause, and connected with a vascular change of the neck. 3. The action is more marked when catarrh is mild, and when acute prostatitis is added to inflammation of the neck of the bladder. In a case of symptomatic priapism, recorded by Dr. Longuet in the Progrès Médical, bromide of camphor was employed with success. Dr. Petrovitz has recorded some very interesting cases of individuals affected with gonorrhœa, in whom painful erections were stopped by the use of capsules of bromide of camphor.

The above facts would seem to show that monobromide of camphor deserves a place in the therapeutics of nervous affections. The number of careful scientific observers who have sifted its merits and tried it clinically is already considerable. The counter-indications of the moderate and methodical use of the drug are few and self.evident, and the only serious drawback seems to reside in its pharnacological preparation. It is not easy to prepare it in the form of syrup, and for children the form of dragées appears the only convenient one. For adults, the form of capsules is preferable to all others; and the observations published in France refer to those of Dr. Clin, which are said to be very strictly dosed and convenient for administration.

\section{ROYAL COLLEGE OF SURGEONS OF ENGLAND.}

AT the meeting of Council on Thursday, amongst other business transacted, the resolution at the former meeting, altering the constitution of the Committee of Reference under the Conjoint Scheme, was rescinded.

* Petrovitz: Etude Clinique sux le Bromuro de Camphre. Montpellier, 1875.

\section{Worespomence.}

"Audi alteram partem."

\section{ON THE USE OF SALICIN IN ACUTE RHEUMATISM.}

To the Editor of THE LANCET.

SIr,-As Dr. Maclagan bas again called attention to the use of Ealicin in acute rheumatism, will you allow me to make a few remarks on his communication?

During the past six months I have treated in this infirmary more than thirty cases of acute rheumatism of all degrees of severity, with salicin, salicylic acid, or its sodium salt. Many of these have been reported in your own columns, and two cases, ending fatally, in the Medicat Times and Gazette a short time since.

First, with regard to the influenve of the drug on cardial complication. In two cases pericarditis ensued while the patient was under the influence of salicin, in the one case having taken from six to a hundred and twenty grains a day for four days, and in the other a hundred and eighty grains a day for three days; neither of the cases being of great severity in other respects.

Secondly, as to the influence of the treatment on recovery. The experience of four cases which proved fatal in spite of active treatment, both specific, by means of salicylic acid, symptomatic by means of quinine and cold baths, precludes me from indulging in the hope that we have entirely mastered this most distressing disease.

At the same time many cases of considerable severity have recovered with remarkable rapidity, and I do not doubt that we have in salicin and its congeners a most useful remedy.

With regard to the comparative merits of salicin and the acid, the former is the more pleasant to take, though it occasionally disagrees, but its high price is some objection to its use in hospital practice. The quantity required, moreover, is larger than that of the acid.

I am, Sir, your obedient servant,

Oetober 31st, 1876.

Frnest H. JACOB, M.B., Resident Physician, Leeds Infirmary.

\section{SPLENO'TOMY.-TREATMENT OF THE INSANE IN AMERICA. \\ To the Editor of THE LANCET.}

SIn,-In recording, in your issue of the $23 \mathrm{rd}$ ult., the Paris case of Splenotomy of last April, you say: "This brings the total number of operations of this kind upors record up to six, two having been performed by M. Péan, the remaining four, we believe, being due to MM. Küchler, Spencer Wells, and Koeberlé; but, strange to say, all have been unsuccessful except the two due to the Parisian surgeon." I beg leave to add to this list three cases (though one is doubtful) recorded by Professor Flint in his "Practice." Writing of splenotomy, he says that "the first case was in Naples in 1549 ; the operation was by Zaccarelli, and the patient recovered. The authenticity of this case is, per. haps, open to distrust. The second was in Germany, in 1826, Quittenbaum operating. Death followed in six hours." Flint refers to an article by Samuel Wilks in Guy's Hospital Reports, vol. xi., 1865, also to London Medical Times and Gazette. January, 1866, and to New York Medical Journal, May, 1866. Flint also records an American case in which about two-thirds of the spleen was removed which was protruding from an orifice made by a bullet. The operation-was done by Dr. Alston, of Texas, in 1861. Dr. A. says that "s the stump which remained plugged up the bullet-hole. No suppuration ensued, and he got well without a bad symptom."

I am glad that you have exposed so well in THE LANCEx the abuses-if I may not say atrocities-of some American insane asylums. There are too few attendants in our asylums, and many of them, both by nature and nurture, are wholly unfit for their service. It was, if it is not now, a common custom at one, at least, of our Massachusetts asylums for attendants to put their patients into straitjackets, so that they themselves might have an evening's 
frolic in the town! You may hardly credit it, but it is nevertheless true of one county, if not more, of Massachusetts that the two physicians required by law to certify that a pauper is insane, and a fit subject for a State asylum, may legally certify this without having seen the pauper! They must either examine him personally-which probably they almost or quite invariably do-or be convinced by the testimony of otbers, who may not be physicians, that he is insane, and certify accordingly! I know this to be true from having seen the official blanks sent to overseers (guardians) of the poor, which doubtless accord with the statute law, and probably are used in case of non-paupers also. It is easy to see what great abuses might arise from the use of such blanks, though none may have arisen. I am, Sir, your obedient servant,

New York, October 20th, 1876. S. P. FowLer, M.D.

\section{"THE USE OF A MAGNET IN THE DETECTION OF A NEEDLE BROKEN IN THE LEG."}

To the Editor of The LaNcET.

SIR,-In your issue of this week I observe an outline of a note by Sir B. C. Brodie on "The Use of a Magnet in the Detection of a Needle broken in the Leg," and as the author appears to think that the matter of his note is a novelty of sufficient importance to make it the suhject of a communication to the Royal Medico-Chirurgical Society, I am thereby induced to report a case of a similar character which occurred in my practice many years ago; the more so as during this week it so happened that the matter has been recalled to my memory by Mr. Marriott, surgeon of the Warneford Hospital in this town, coming to ask me if I still had the magnet I had then used, as be wished to try it in a similar case. Several years ago I had mentioned the case to him, and advised him to try it if opportunity offered.

In 1864, while on foreign gervice (being at that time on the Army Medical Staff) at Cowsal, in Central America, and being the only English surgeon within a radius of 150 miles, a Spaniard came to me who had by mischance broken off half of a needle in the palm of his right hand. I made a small incision, bearing in mind the arterial relations of that part, and carefully searched for the broken point, but I could not find the needle. I had then by me a small natural magnet of loadstone, which is, I believe, a magnetic iron ore. After enlarging the incision a little, I placed the stone over it, rolled over it many layers of bandage, and told the patient to come again in twenty-four hours. On examining it after tinis period had elapsed, and removing the bandages with care, and gently raising the stone (about one inch equare), I saw the end of the broken fragment sticking up in the wound, much blackened, and easily removed it with an ordinary dressing forceps.

I have twice since, with an ordinary horseshoe magnet, bound over the part after a superficial incision, succeeded in the same way. It seemed to me such a natural method of proceeding that I supposed it was the common thought of all surgeons. It appears I was mistaken, and it only gives me another proof that there of ten happens in the details of general practice many interesting surgical events which are passed over without record. In my many wanderings while in the service $I$ have lost this piece of loadstone, but the lesson I then learnt in 1864 has never been forgotten. I can fully endorse the remarks made by Dr. De Chaumont in his address, which you report, that army surgeons ought to be fertile in expedient as well as competent to execute, as no men in our profession have greater responsibilities. Yours truly,

Leamington, October 29th. James Thompson, M.B. Late Army Medical Staff.

\section{" ON THE RETENTION OF THE CATHETER AFTER INTERNAL URETHROTOMY."}

To the Editor of The LANCET.

Sin,-In your publication of October 28th, 1876, Mr. Teevan, in a letter to you on the above subject, assumes that I stated that it was not the practice at the general hospitals to leave a catheter in the bladder after internal uretbrotomy." I beg to say that my remark referred solely to my own individual experience, and I did not even allude to what might be generally done in London. I spoke to this effect, and almost in these words: Personally, whether after internal or external urethrotomy or aplitting, I only kept a catheter in the bladder when hæmorrhage was deemed to be probable. Yours, \&c.,

Queen Anne-street, W., November 5th, 1876 .

C. F. Maunder.

\section{HOSPITAL SUNDAY AT WORCESTER. (From a Correspondent.)}

ON Sunday last the ancient city of Worcester held its fifth "Hospital Sunday," when in almost all the places of worship within the city, and in numerous churches and chapels of the county, collections were made on behalf of the three medical charities in Worcester-namely, the infirmary, the dispensary, and the ophthalmic institution. Hitherto from $£ 600$ to $£ 700$ have been realised from each of these annual collections, whereof the infirmary has naturally obtained the lion's share. Looking at the area of collection, $\$ 700$ does not appear to represent an excessive liberality on the part of the congregations appealed to, and a glance at the long list of sums received from the several contributories in 1875 suggests the probability that the claims of medical charities have yet to be adequately understood in many quarters.

The Bishop of Worcester, a warm supporter of the movement, advocated its cause on Sunday morning in the church of St. Nicholas, and in the evening, the Rev. J. R. Young, honorary Canon of Worcester, preached to a large congregation assembled in the nave of the catbedral. Rarely is the protession privileged to hear so elnquent and outspoken a tribute to the value of the services which it renders to mankind as fell from the lips of Canon Young on this occasion. From the text "I was sick, and ye visited me," excellent practical lessons were deduced as bearing upon the special object of the discourse; and referring to the existence of institutions for the relief of sickness and disease, Canon Young declared that, excepting the medical profession, there was none other which deliberately set aside a large portion of valuable time for the gratuitous exercise of knowledge and skill for the benefit of suffering humanity. He knew, he said, it might be cynically ob. served, that self-interest was at the bottom of the ap. parently self-sacrificing labours of the doctor, but he repudiated the idea as being in any wide sense applicable. The soothing influence of the doctor's visit to the patient was touched upon and illustrated with force and wisdom; and Canon Young did not hesitate to remind the clergy that it would be well for them to adopt in their sacred ministrations as much as possible of the kindly tone and hopeful reassuring method of the doctor.

Worcester, October 31st, 1876

\section{THE NEWCASTLE-ON-TYNE SCHOOL OF MEDICINE \\ (From a Correspondent.)}

Tre number of medical students in this important town is over sixty. A casual visit to it produces the impression that Newcastle either is or ought to be a very good school of medicine. The hospital contains about 240 beds, and has lately been very much improved. It is situated between the two populous counties of Northumberland and Durham, and in the very centre of the great North-E tstern Railway system. The new operating theatre is perhaps the most beautiful one in the kingdom, lighted from the roof as well as from the sides. I was fortunate in making my visit on an operating day. There was an operation for stone by Dr. Arnison on a child, as well as amputation of a breast for fungoid disease. Dr. Heath excised the hip-joint, and amputated at the knee. There were several other operations, Stone cases are very common here, and are very successful. Death is scarcely known after lithotomy, which is preferred, as a rule, to lithotrity. What impressed me most favourably in the hospital was the excessive care and trouble with which the antiseptic treatment was applied. It would have done 